TI 2016-057/VI

Tinbergen Institute Discussion Paper

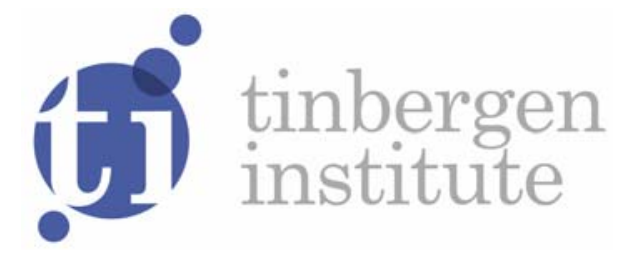

\title{
Trade Policy Options of Ukraine: East or West
}

Irena Mikolajun'

Richard Paap'

Jean-Marie Viaene'

Olga Zelenko

1 Erasmus School of Economics, Erasmus University Rotterdam, and Tinbergen Institute, the Netherlands;

2 Argenta Spaarbank, The Netherlands. 
Tinbergen Institute is the graduate school and research institute in economics of Erasmus University Rotterdam, the University of Amsterdam and VU University Amsterdam.

More TI discussion papers can be downloaded at http://www.tinbergen.nl

Tinbergen Institute has two locations:

Tinbergen Institute Amsterdam

Gustav Mahlerplein 117

1082 MS Amsterdam

The Netherlands

Tel.: +31(0)20525 1600

Tinbergen Institute Rotterdam

Burg. Oudlaan 50

3062 PA Rotterdam

The Netherlands

Tel.: +31(0)10 4088900

Fax: +31(0)10 4089031 


\title{
Trade Policy Options of Ukraine: East or West
}

\author{
Irena Mikolajun* Richard Paap ${ }^{\dagger} \quad$ Jean-Marie Viaene ${ }^{\ddagger} \quad$ Olga Zelenko ${ }^{\S}$
}

July 26, 2016

\begin{abstract}
The dissolution of the Soviet Union in 1991 has led to the independence of fifteen new states. Twelve of these, including Ukraine, joined the Commonwealth of Independent States (CIS) whose goal was to form a common economic space with free movement of goods, labor and capital. Twenty five years later, CIS countries still face important trade policy choices the implementation of which is conditional on the quality of governance and infrastructure. The evaluation of these policy choices gains therefore considerable importance. Using an unbalanced panel data set of bilateral export flows among 159 economies we estimate the gravity model of trade using alternative estimation approaches that account for zeros in trade: Heckman, Poisson pseudo-maximum likelihood and Martin-Pham tobit. Our empirical results show robust outcomes and advocate importance of WTO membership, governance and effective distance (corrected for infrastructure). Using scenario analyses we assess counterfactuals for Ukraine and find, for example, that improved infrastructure would on average lead to a $22 \%$ increase in Ukrainian exports while improved governance would, ceteris paribus, almost double its trade. Most of these changes originate from the intensive margin of trade.
\end{abstract}

JEL Classification: C23, F13, F14, F17, F31, F33, O43

Keywords: extensive/intensive margins, governance, gravity model, infrastructure, regional trade agreements, zero trade

\footnotetext{
*Tinbergen Institute, 3000 DR Rotterdam, The Netherlands; Tel.: +31-64-9974434; E-mail: mikolajun@ese.eur.nl, irena.mikolajun@gmail.com

${ }^{\dagger}$ Erasmus School of Economics, 3000 DR Rotterdam, The Netherlands; Tel.: +31-10-4081315; E-mail: paap@ese.eur.nl

${ }^{\ddagger}$ Erasmus School of Economics, 3000 DR Rotterdam, The Netherlands; Tel.: +31-10-4081397; E-mail: viaene@ese.eur.nl

$\S$ Argenta Spaarbank, 4815 NG Breda, The Netherlands; Tel.: +31-76-5433085; E-mail: olga.zelenko@argenta.nl
} 


\section{Introduction}

December 1, 2016 will mark the 25th anniversary of the dissolution of the Soviet Union and the proclamation of fifteen new independent states. In this time span, former Soviet countries faced the troublesome transition from planned to market economies and went through reforms in institutional, political and social spheres. Some countries celebrated the independence they re-gained and quickly set their priorities on the integration with the European Union. Other newly proclaimed states were keen to preserve former economic ties. The latter, including Ukraine, founded the Commonwealth of Independent States (CIS), an agreement whose goal was to form a common economic space with free movement of goods, services, labour and capital. ${ }^{1}$

Over the years, the ruling system of Ukraine meandered through the contested grounds of ideologies, namely those of a post-soviet state and those of modern European nations. On the one hand, with the enlargement rounds of 2004 and 2007 the borders of the European Union (EU) came closer to Ukraine, making the EU a potentially more important trading partner. On the other hand, pro-soviet governments ratified numerous bilateral agreements between subsets of CIS countries in search of deeper integration. However, by bringing down their president in winter 2013, the Maidan revolution prevented the planned membership of Ukraine in the customs union initially founded by Belarus, Kazakhstan and Russia in 2007. The revolution, however, did not renege other regional trading agreements already in place. In contrast, it prompted the signing of the so-called Deep and Comprehensive Free Trade Agreement with the EU in 2014 as a new source of prosperity. Therefore, the question of what deeper economic ties with the Western nations may bring to Ukraine takes considerable importance. Particularly, what are the factors suggesting that deeper economic integration of Ukraine with the EU may well outweigh the benefits from further advancement of economic ties with the rest of CIS? The objective of this paper is to address these trade-offs empirically by focusing on the trade implications of alternative policy choices. $^{2}$

Several other aspects that characterize Ukraine's evolution are considered here as well. First, the quality of infrastructure is important in the determination of trade flows (Francois and Manchin, 2013; Grigoriou, 2007; Shepherd and Wilson, 2009) in that it can effectively lower the distance between two even geographically distant countries. Second, Acemoğlu and Robinson (2012) show that inclusive political institutions that support inclusive economic institutions are more likely to lead to prosperity. It is the connection between polit-

\footnotetext{
${ }^{1}$ Though country membership in CIS varied over time, our definition includes the 12 countries that were members in 1993, i.e. Armenia, Azerbaijan, Belarus, Georgia, Kazakhstan, Kyrgyzstan, Moldova, Russia, Tajikistan, Turkmenistan, Ukraine and Uzbekistan. Georgia joined in 1993 but quit in 2009. Turkmenistan was a member throughout 1991-2004.

${ }^{2}$ Though the analysis of this paper considers trade flows, the latter are closely linked to the growth experience of countries. For example, Harrison and Rodríguez-Clare (2009) describe 176 studies that use a reduced form relationship between openness and economic growth. Most of the studies they review find a positive relationship between trade volumes and growth. Equally important is the abundance of studies that test for the positive role of FDI on country's growth.
} 
ical and economic institutions which can explain why otherwise similar-looking countries might differ in terms of economic performance. In addition, good institutions as a means of protecting property rights promote entrepreneurship as they facilitate the adoption and creation of new technologies (Hausmann and Rodrik, 2003). Also, there is substantial evidence that the quality of political and economic institutions matters for trade. For example, Cuñat and Melitz $(2010,2012)$ focus on labor market regulations and show the role of labor market flexibility as a source of comparative advantage. Levchenko (2004) studies the quality of institutions (like the imperfect recognition of property rights, the quality of contract enforcement, etc.) and shows how it affects trade flows and the distribution of gains between rich and poor countries. In Nunn (2007), Costinot (2009) and others, institutional differences across countries have consequences not only for aggregate productivity but also for productivity differences across industries within a single country. Altogether it is not surprising that democratic values and, in particular, a war on corruption ${ }^{3}$ matter for the establishment of closer ties with the World Trade Organization (WTO) and the EU. In this analysis, we use indicators to quantify the effects of governance and infrastructure on trade and address the following questions: (i) Would the improvement of governance and infrastructure yield a significant positive impact on Ukraine's trade? (ii) How large are these effects in comparison to traditional benefits, if any, of standard trade policies like regional trade agreements?

We estimate gravity models of trade using an unbalanced panel data set that consists of bilateral export flows among world economies. The data covers 159 countries over the period 1997 - 2012 and thus includes the major developments over the past decades. While the existing literature aims at measuring general effects of trade policies, this paper focuses rather on the assessment of counterfactuals using a novel technique for non-linear scenario analysis that accounts for the intensive and the extensive margins of trade. Although the analysis can be potentially extended to any world country, our focus is on Ukraine.

Different econometric techniques have been advanced recently to correct for estimation biases that arise from the large number of zero flows typical to bilateral trade data. ${ }^{4}$ There are several reasons for the occurrence of zeros. A first cause is the so-called data coding problem in survey data (Wooldridge, 2002) where some of the zeros are attributed to the non-reporting of small trade flows. Further, political conflicts can give rise to the absence of trade between different subsets of countries. For example, there is no trade between Azerbaijan and Armenia due to their conflict over the Nagorno-Karabakh region. ${ }^{5}$ Finally, with sunk entry and sunk exit costs in export markets it might be optimal for exporting firms not to export as it has been shown in the hysteresis literature (see, e.g. Dixit, 1992) and the firm heterogeneity literature (see, e.g. Helpman et al., 2008). In this paper we use

\footnotetext{
${ }^{3}$ On the dynamics of corruption in Ukraine see The Economist (Sep 26, 2015; pp. 23-24).

${ }^{4}$ Together with the decomposition of aggregate exports into the extensive/intensive margins, Head and Mayer (2014) consider the econometric treatment of zero trade flows to be another topic at the frontier of current research. As section 4 will show both topics are related.

${ }^{5}$ In contrast, trade transactions did not stop after the armed conflict between Georgia and Russia.
} 
recent estimation techniques that take into account zeros in trade. Our approach is then to select between rival models using statistical tools for model selection like the Vuong test.

Our empirical results convincingly support: (i) higher values for exports between CIS countries; (ii) a positive effect of WTO membership on trade of the order of $24-40 \%$; (iii) significant positive effects of improved institutions and infrastructure. For Ukraine scenario-based estimates of the effects of improved institutions on trade are about $98 \%$, those of improved infrastructure are about $22 \%$.

The remainder of this paper is organized as follows. Section 2 reviews relevant economic indicators for Ukraine. Section 3 discusses the modelling approach, the data and the results. Section 4 uses estimation results to compute counterfactuals and assess potential effects of improved governance and improved infrastructure on Ukraine's export flows. Section 5 addresses the policy relevance of our results. Section 6 concludes. The Appendix describes the data methods and sources, includes the list of countries in our panel, provides details on the estimation of relevant models and describes the algorithms used for the analysis of counterfactuals.

\section{Trade and Economic Development Patterns in Ukraine}

Ukraine has undergone a difficult and lengthy transition from a planned to a market economy. ${ }^{6}$ Since its independence from the Soviet Union in 1991 the country had experienced steeply declining real economic activity for eight years. Although the trend reversed since then Ukraine's real output in 2014 was yet lower than its level 24 years ago. This is in contrast to growth experience of any other CIS economy. ${ }^{7}$ Ukraine is currently a lowermiddle-income economy according to the World Bank classification.

Income inequality, however, has decreased since mid-1990s. The most recent GINI coefficient for Ukraine is $28.2 \%$ which is lower than the average value of the remaining CIS countries (see Table 1). The summary of selected indicators in Table 1 also shows that Ukraine is an outward oriented economy. Trade openness measured by trade-to-GDP is $77 \%$. The indicator is considerably higher than the CIS average of $46 \%$. The country is also a WTO member since 2008 and on average participates in 16 RTAs. Furthermore, it applies an average tariff rate of $2.6 \%$, which is similar in value to that of the EU while it is considerably lower than the tariff rate applied by the rest of CIS. Trade, however, is hampered by a relatively poor quality of trade and transport-related infrastructure. The World Bank logistics performance index rates Ukraine 2.7 on the scale from 1 to 5 (see Table 1).

Concerning trading partners, Ukraine trades a similar amount with the CIS free trade

\footnotetext{
${ }^{6}$ This is regardless of its high economic potential. For example, the large and educated population of the country, availability of natural resources, favourable geographic position between the East and the West. In $199062 \%$ of Ukraine's adult population had at least secondary degree (see Barro and Lee, 2014) and this percentage has increased over time.

${ }^{7}$ Similar performance can only be observed for Moldova where real GDP in 2014 has also been lower than in 1991.
} 
Table 1: Trade and economic development indicators in Ukraine, EU-15 and CIS.

\begin{tabular}{lcrcc}
\hline \hline Indicator & Ukraine & EU-15 & EU-27 & $\begin{array}{c}\text { CIS (excl. } \\
\text { Ukraine) }\end{array}$ \\
\hline \hline GNI per capita (PPP, 2011 international \$) & 10055 & 39684 & 32551 & 10872 \\
GINI coefficient (\%) & 28.2 & 29.4 & 30.0 & 33.9 \\
Governance (average score) & -0.72 & 1.32 & 1.06 & -0.80 \\
Logistics performance index & 2.7 & 3.9 & 3.5 & 2.4 \\
Trade openness (\%) & 77.0 & 63.3 & 66.7 & 46.4 \\
Tariff (\%) & 2.6 & 2.4 & 2.4 & 6.8 \\
Percentage of WTO members & 100 & 100 & 100 & 50 \\
Number of regional trade agreements (average) & 16 & 35 & 35 & 7 \\
\hline \hline
\end{tabular}

Source: World Bank, CIA Factbook, WTO.

Notes: (i) EU-15 includes 15 economies that joined the EU before 1996. EU-27 includes 27 economies that joined the EU before 2008. CIS (excl. Ukraine) refers to 10 CIS economies: Armenia, Azerbaijan, Belarus, Kazakhstan, Kyrgyz Republic, Moldova, Russia, Tajikistan, Turkmenistan and Uzbekistan; (ii) The data refers to year 2013 for all indicators except the logistics performance index (2012 data) and the GINI coefficient (2005-2013 data); (iii) Governance is the average score of 6 World Bank WGI indicators that range from $-2.5=$ low to $2.5=$ high (see Appendix A.2 for more details); (iv) Logistics performance is the World Bank index that measures the quality of trade and transport-related infrastructure (ranges from $1=$ low to $5=$ high); $(v)$ Trade openness is the sum of regional merchandise exports and imports divided by regional GDP, all in current US $\$ ;(v i)$ Tariff is the average of effectively applied tariff rates weighted by the product import shares.

area (CISFTA) as it does with the EU (Figure 1). In 2013 trade with CISFTA constituted $30.6 \%$ of total Ukrainian trade. Most of it (89.3\%) is Ukraine's trade with Russian Federation, which is Ukraine's largest single country trading partner. Trade with CISFTA is certainly facilitated by a common historical past with CIS, common borders with Belarus, Moldova and Russia and a common language shared by significant parts of Ukrainian population. Nevertheless, the share of Ukrainian trade with the EU is close in value. Main goods exported to the EU are raw materials, chemical products and machinery while main imported goods include machinery, transport equipment, chemicals, and manufactured goods. ${ }^{8}$ Thus, both EU-27 and CISFTA are important country's trading partners although it is evident from Figure 1 that the share of CISFTA has been on a steady decline since 2011.

\footnotetext{
${ }^{8}$ See http://ec.europa.eu/.
} 
Figure 1: Ukraine's trade with EU-27 and CISFTA. (percentage of total trade)

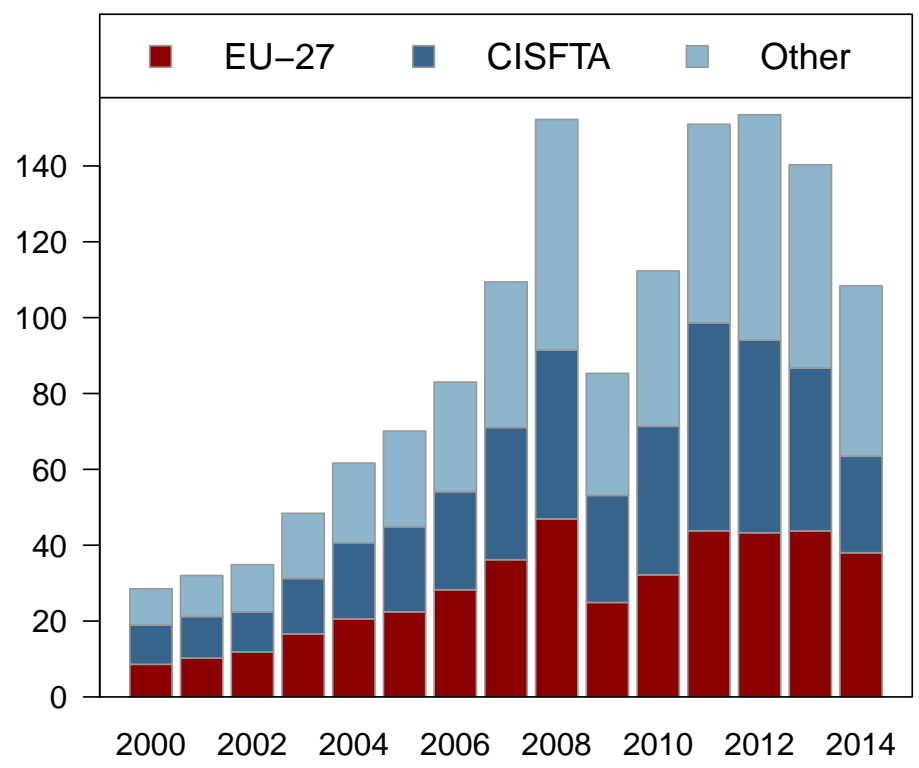

Source: Own calculations based on IMF DOTS.

Notes: (i) Other countries include mainly China, Turkey and Egypt; (ii) CISFTA consists of Armenia, Kazakhstan, Kyrgyzstan, Moldova, Russia, Ukraine and Uzbekistan.

An aspect of great importance for Ukraine to establish closer ties with the EU is the quality of institutions. Currently Ukraine performs considerably poorer than the EU. The average score on the quality of governance is low and similar in value to that of CIS (see Table 1). A particularly low score is on control of corruption. Corruption is perceived to be extensive in the Ukraine's public sector. The country scores -1.09 in 2013 on the scale of -2.5 (high corruption) to 2.5 (low). According to Transparency International the country ranks 142 out of 174 world countries in the 2013 Corruption Perceptions Index. Rule of law indicator is also low ${ }^{9}$ and reveals limited confidence in the quality of contract enforcement, property rights, courts and police. Clearly, corruption and weak regulations are deterrents to trade and foreign investment. Importantly, however, a pro-European choice of the foreign policies of Ukraine would certainly help to bring its current governance scores to a higher level.

\section{Model Selection, Estimation and Results}

We analyze Ukraine's trade flows in a gravity model framework. Gravity equation is the result of the most modern microfounded trade models. It has been obtained in the literature that assumes product differentiation and imperfect competition (Anderson, 1979; Helpman and Krugman, 1985; Bergstrand, 1989; Anderson and van Wincoop, 2003), in the litera-

\footnotetext{
${ }^{9}$ The score is -0.83 in 2013.
} 
ture that builds on perfect competition and technological differences (Eaton and Kortum, 2002) and in the literature that builds on perfect competition and complete specialization (Deardorff, 1998). The equation takes the following functional form:

$$
X_{i j t}=Y_{i t} Y_{j t} \frac{\tau_{i j t}^{1-\sigma}}{\sum_{i t} \Delta_{j t}},
$$

where $X_{i j t}$ is a measure of nominal trade between two countries $i$ and $j$ at time $t$. In this paper we measure trade by export flows from exporting country $i$ to importing country $j$. To estimate the parameters of the gravity model, we use an unbalanced panel of annual bilateral export flows between 159 countries and 155 trading partners over 1997-2012. Altogether the included countries cover over $94 \%$ of reported world exports in 2012. Variables $Y_{i t}$ and $Y_{j t}$ capture the sizes of the trading partners. We use exporting and importing country's gross domestic products as proxies for $Y_{i t}$ and $Y_{j t}$. The term $\tau_{i j t}$ denotes trade costs between the two countries. The costs include transportation costs (e.g., distance and infrastructure), information and search costs (e.g., common language, common historical ties) and a variety of trade policy measures (e.g. tariff rates, membership in WTO, free trade areas or customs unions) that either lower or raise the costs associated with trade. The two terms in the denominator $\Sigma_{i t}$ and $\Delta_{j t}$ are additional terms that vary over time and at country $i$ and country $j$ level, respectively. In Anderson and van Wincoop (2003), for example, these are the terms that capture multilateral price resistance and in Head and Mayer (2014) the different ways to proxy these multilateral resistance terms are listed and reviewed. Table 2 itemizes the variables included into final model specifications. More details on the included countries and the data sources can be found in Appendices A.1 and A.2, respectively.

\subsection{Zeros in Trade}

On average around one forth of country pairs in the world exhibit zero trade (see Table 3). Although the number of trading country pairs is declining over time and each year more and more countries engage into trade, accounting for zeros is important to avoid possibly biased inference (see, e.g., Helpman et al., 2008). Zeros occur for a variety of reasons. It may be that trade between two specific countries is small and therefore appears as null in reported data due to rounding. Alternatively, it may be that countries do not trade indeed either because of political conflicts or because firms find it optimal not to trade. Melitz (2003), in fact, explains emergence of zero trade flows as a result of firms' self-selection into exporters and non-exporters. As also in later trade models with self-selection (Bernard et al., 2007; Chaney, 2008; Arkolakis, 2011) firms decide whether to export based on fixed costs of trade that need to be carried on. As a result zero trade in the exporting country is observed when no firms find it profitable to carry on the fixed costs. Depending on the source of zeros, different econometric methods are applicable to estimate the parameters in (1). In this paper we use the three most commonly encountered techniques: Heckman two- 
Table 2: Explanatory variables included in the final model specifications.

\begin{tabular}{|c|c|}
\hline Notation & Variable \\
\hline $\ln G D P_{i t}$ & log of GDP of exporting country $i$ in current million US dollars at time $t$ \\
\hline $\ln G D P_{j t}$ & log of GDP of importing country $j$ in current million US dollars at time $t$ \\
\hline effdist $t_{i j t}$ & $\begin{array}{l}\text { effective (corrected for infrastructure) distance between countries } i \text { and } j \text { at } \\
\text { time } t\end{array}$ \\
\hline $\operatorname{tariff} f_{j t}$ & average tariff rate in percent applied by importing country $j$ at time $t$ \\
\hline$g_{\text {ov }}$ it & $\begin{array}{l}\text { average score on six World Bank governance indicators for exporting country } i \\
\text { at time } t\end{array}$ \\
\hline$g o v_{j t}$ & $\begin{array}{l}\text { average score on six World Bank governance indicators for importing country } j \\
\text { at time } t\end{array}$ \\
\hline$W T O_{i j t}$ & $\begin{array}{l}1 \text { when both countries } i \text { and } j \text { are WTO members at time } t \\
0 \text { otherwise }\end{array}$ \\
\hline$E U_{i j t}$ & $\begin{array}{l}1 \text { when both countries } i \text { and } j \text { are EU members at time } t \\
0 \text { otherwise }\end{array}$ \\
\hline$C U B K R_{i j t}$ & $\begin{array}{l}1 \text { when both countries } i \text { and } j \text { are members of the customs union between } \\
\text { Belarus, Kazakhstan and Russia at time } t \\
0 \text { otherwise }\end{array}$ \\
\hline EUFT $A_{i j t}$ & $\begin{array}{l}1 \text { when country } i \text { is an EU country and country } j \text { has an FTA with EU at time } \\
t \text { and vice versa } \\
0 \text { otherwise }\end{array}$ \\
\hline$C I S_{i j t}$ & $\begin{array}{l}1 \text { when both countries } i \text { and } j \text { belong to CIS at time } t \\
0 \text { otherwise }\end{array}$ \\
\hline language $_{i j}$ & $\begin{array}{l}1 \text { when a common language is spoken by at least } 9 \% \text { of the population in coun- } \\
\text { tries } i \text { and } j \\
0 \text { otherwise }\end{array}$ \\
\hline adjacent $_{i j}$ & $\begin{array}{l}1 \text { when countries } i \text { and } j \text { share a common border } \\
0 \text { otherwise }\end{array}$ \\
\hline religion $_{i j}$ & religion similarity between country $i$ and $j$ \\
\hline
\end{tabular}

Note: See Appendix for more details on data sources and methods.

stage procedure (Heckman, 1979), Eaton-Tamura tobit (Eaton and Tamura, 1994) and Poisson pseudo-maximum likelihood (PPML) (Santos Silva and Tenreyro, 2006). ${ }^{10}$ The first two - Heckman two-stage procedure and Eaton-Tamura tobit - are directly built under the assumption that firms self-select into export markets. Both models allow to carry out an extensive comparative statics in that both intensive and extensive margins of trade can be computed. The latter - PPML - is an alternative to self-selection models. It accounts for zero trade flows assuming that zeros occur at random. An advantage of using PPML is that it eliminates the bias that arises due to the log-linearization of trade flows in the presence of heteroskedasticity. However, unlike, for example, the Heckman model, PPML postulates identical data generating processes for trading and non-trading country-pairs.

As selecting from the three types of specification is difficult due to the different distributional assumptions, we apply in this paper all three specifications and compare the implied results from the models. We however perform a model selection procedure within each model family to select the proper specification of intercepts and explanatory variables.

\footnotetext{
${ }^{10}$ Other methods are available as well, e.g., negative binomial, but they are generally special cases or extensions of the models discussed in this section and are significantly less encountered in the empirical literature.
} 
Table 3: Occurence of zero trade flows.

\begin{tabular}{cccc}
\hline \hline Year & $\begin{array}{c}\text { Number of country } \\
\text { pairs with positive } \\
\text { export flows }\end{array}$ & $\begin{array}{c}\text { Number of country } \\
\text { pairs with zero } \\
\text { export flows }\end{array}$ & $\begin{array}{c}\text { Zero export flows } \\
(\%)\end{array}$ \\
\hline \hline 1997 & 10633 & 4204 & 28.3 \\
1998 & 11183 & 4307 & 27.8 \\
1999 & 12010 & 4100 & 25.5 \\
2000 & 12571 & 4777 & 27.5 \\
2001 & 13898 & 5481 & 28.3 \\
2002 & 14731 & 5776 & 28.2 \\
2003 & 14993 & 5557 & 27.0 \\
2004 & 15270 & 5390 & 26.1 \\
2005 & 15830 & 5075 & 24.3 \\
2006 & 16152 & 4679 & 22.5 \\
2007 & 16328 & 4536 & 21.7 \\
2008 & 15997 & 4371 & 20.4 \\
2009 & 15602 & 3998 & 19.5 \\
2010 & 13203 & 3198 & 18.0 \\
2011 & 10359 & 2280 & 17.5 \\
2012 & 9668 & 2054 & \\
\hline \hline
\end{tabular}

Source: Own caclulations based on IMF DOTS.

Notes: $(i)$ Calculations are based on nominal bilateral export flows in US dollars; (ii) Country pairs with reported missing export values were omitted.

\subsection{Model Specification and Selection}

Heckman model (Heckman, 1979) assumes that whether two specific countries engage into trade is determined by a latent variable $Z_{i j t}$ (propensity to trade). This unobserved factor linearly depends on a vector of explanatory variables $\mathbf{W}_{i j t}^{\top}$ :

$$
Z_{i j t}=\mathbf{W}_{i j t}^{\prime} \beta+\epsilon_{i j t, 1}
$$

where $\epsilon_{i j t, 1} \sim N I D(0,1)$ and the parameter vector $\beta$ describes the effect of the explanatory variables on the propensity to trade. As long as the propensity to trade is positive, positive trade flows are observed. Otherwise, trade flows are zero:

$$
X_{i j t}^{*}=\left\{\begin{array}{ll}
1 & \text { if } \quad Z_{i j t}>0 \\
0 & \text { if } \quad Z_{i j t} \leq 0
\end{array} .\right.
$$

Here $X_{i j t}^{*}$ is a binary variable that is 0 for country pairs with zero bilateral trade and 1 otherwise. When $X_{i j t}^{*}=1$ positive trade flows $X_{i j t}$ are observed. It is then possible to take the $\log$ of the gravity equation (1) which gives a $\log$-log relationship between existing trade and its determinants:

$$
\ln X_{i j t}=\mathbf{V}_{i j t}^{\prime} \alpha+\eta_{i t}+\eta_{j t}+\epsilon_{i j t, 2}
$$


where $\mathbf{V}_{i j t}^{\prime}=\left(\ln Y_{i t}, \ln Y_{j t}, \ln \tau_{i j t}\right)^{\top}, \eta_{i t}=-\ln \Sigma_{i t}$ and $\eta_{j t}=-\ln \Delta_{j t}$ and where $\epsilon_{i j t, 2}$ is an error term potentially correlated with $\epsilon_{i j t, 1}$. The parameters of (4) can be estimated using ordinary least squares after accounting for the correlation between $\epsilon_{i j t, 1}$ and $\epsilon_{i j t, 2}$ (see Appendix A.3). In some studies, the term $\eta_{i t}+\eta_{j t}$ is replaced by $\eta_{i}+\eta_{j}+\eta_{t}$.

Just as in the Heckman model, bilateral exports $X_{i j t}$ in Eaton-Tamura framework (Eaton and Tamura, 1994) are determined by the latent propensity to trade $Z_{i j t}$. As long as it is positive, positive trade flows between two countries are observed:

$$
X_{i j t}=\left\{\begin{array}{lll}
Z_{i j t} & \text { if } & Z_{i j t}>0 \\
0 & \text { if } & Z_{i j t} \leq 0
\end{array} .\right.
$$

In Eaton-Tamura model the latent variable $Z_{i j t}$ is defined as

$$
\ln \left(Z_{i j t}+a_{t}\right)=\mathbf{V}_{i j t}^{\prime} \alpha+\eta_{i}+\eta_{j}+\eta_{t}+u_{i j t}
$$

with $u_{i j t} \sim N I D\left(0, \sigma^{2}\right)$. It is clear from (5) that the right hand side has to reach a certain time-varying threshold level $\ln a_{t}$ before actual trade takes place. This is a typical outcome of oligopoly models of trade where entry sunk costs must be covered before profitable trade transactions can be established. The possibility to estimate this threshold is clearly an advantage of this method. To capture possible deviations from homoskedasticity in the error term of (5) we follow Martin and Pham (2015) and we replace $\sigma$ by $\sigma_{i j t}$ and let it depend on regressors in the following manner:

$$
\sigma_{i j t}=\xi+\delta\left(\mathbf{V}_{i j t}^{\prime} \alpha+\eta_{i}+\eta_{j}+\eta_{t}\right)
$$

To estimate the parameters we can use maximum likelihood approach, see again Appendix A.3 for details.

Estimation of trade elasticities by using a log-log functional form as in Heckman has its limitations. Santos Silva and Tenreyro (2006) show that when errors are heteroskedastic the $\log$ - $\log$ specification of the gravity equation leads to biased parameter estimates due to Jensen's inequality. We therefore follow the authors and as a yet another estimation method use PPML to overcome potential bias. The method is essentially Non-Linear Least Squares when the conditional variance of trade flows $\operatorname{Var}\left(X_{i j t} \mid \mathbf{V}_{i j t}^{\prime}\right)$ is proportional to the conditional mean $E\left(X_{i j t} \mid \mathbf{V}_{i j t}^{\prime}\right)$ :

$$
X_{i j t}=e^{\mathbf{V}_{i j t}^{\prime} \alpha+\eta_{i}+\eta_{j}+\eta_{t}}+\nu_{i j t} .
$$

Details on parameter estimation can be found in Appendix A.3. Besides accounting for the bias associated with Jensen's inequality, the method does not pose restrictions to the inclusion of zero trade country-pairs and, in addition, it does not specify the distribution of $\nu_{i j t}$.

All three methods allow for a large range of specifications of the deterministics and the 
inclusion of explanatory variables. Some authors opt for country-pair fixed effects to control for unobserved heterogeneity in country pairs (e.g., Cheng and Wall, 2005). Others employ country fixed effects (e.g. Mátyás, 1997; Egger, 2000). Yet others estimate time-varying country fixed effects or a combination of those (e.g., Baltagi et al., 2003). Furthermore, the use of both nominal and real trade data is common. Although the gravity equation is a demand function in value terms Glick and Rose (2002), Baltagi et al. (2003) among others choose to use real trade flows in their empirical studies. In this case, however, the way nominal bilateral trade flows are deflated to obtain real data is important as this may well affect the accuracy of estimates when panel data is used (see, e.g., the bronze medal mistake in Baldwin and Taglioni, 2007).

In this paper we do not choose a particular specification but instead let the data choose between alternative models using statistical tests. This allows us to directly address the following important choices that have to be made in the empirical analysis of trade flows: (i) What is the best specification of fixed effects to capture unobserved heterogeneity in bilateral trade? Should the correct empirical specification of gravity equation include timevarying country effects directly prescribed by economic theory? (ii) How do gravity models of trade with nominal variables compare to gravity models of trade with real variables? Should nominal gravity model specifications be preferred? (iii) Is bilateral trade data characterized by homoskedasticity? Do models that allow for heteroskedastic errors perform equally well to models that assume error homoskedasticity? We address all these questions in our empirical analysis.

To select the proper model specification we use statistical tests. When two rival models are nested we apply a regular log-likelihood test. When the two are non-nested we proceed with the Vuong test (Vuong, 1989; Clarke, 2007). The Vuong test cannot be applied for PPML and Heckman models as parameter estimation in these models does not involve a full maximum likelihood approach. However, for the choice of nominal and, separately, real variables, we still apply the Vuong test in the Heckman model using the likelihood of the second stage. This approach seems reasonable as the first step estimation results are identical irrespective of the fixed effects specification in the second step. In the case of PPML we compare and report the results of all model specifications. To investigate the difference in coefficients we also report the results of truncated PPML models that are estimated using a subset of positive trade flows.

\subsection{Empirical Results}

We estimate the parameters of the three families of gravity specifications, that is, the Heckman specification, the Eaton-Tamura framework and the PPML approach. Within each family we select the best model specification as discussed in the previous section. Columns (1)-(4) of Table 4 provide the parameters estimates for three possible specifications of the Heckman model using nominal data. The Vuong test indicates that the model with country-pair and time fixed effects is significantly better than the other two specifications, 
see the first panel of Table 5. This also holds for the case where we use real data instead of nominal data. The parameters estimates for the real specification are given in Table A.2.

For the Eaton-Tamura framework we consider specifications with time-invariant and time-variant entry costs, homoskedastic and heteroskedastic errors and nominal and real variables. Statistical tests indicate that the Martin-Pham specification with time-varying entry costs $a_{t}$ is preferred, see third panel of Table 5 . The nominal Martin-Pham model with time-variant entry costs significantly outperforms 6 out of 7 or $86 \%$ of its competitors in pairwise model comparisons. The same holds for its real counterpart. Parameter estimates of this specification can be found in the final column of Table 4 for the nominal specification and Table A.2 for the real specification, respectively.

Table 4: Estimates of the gravity model using alternative estimation techniques.

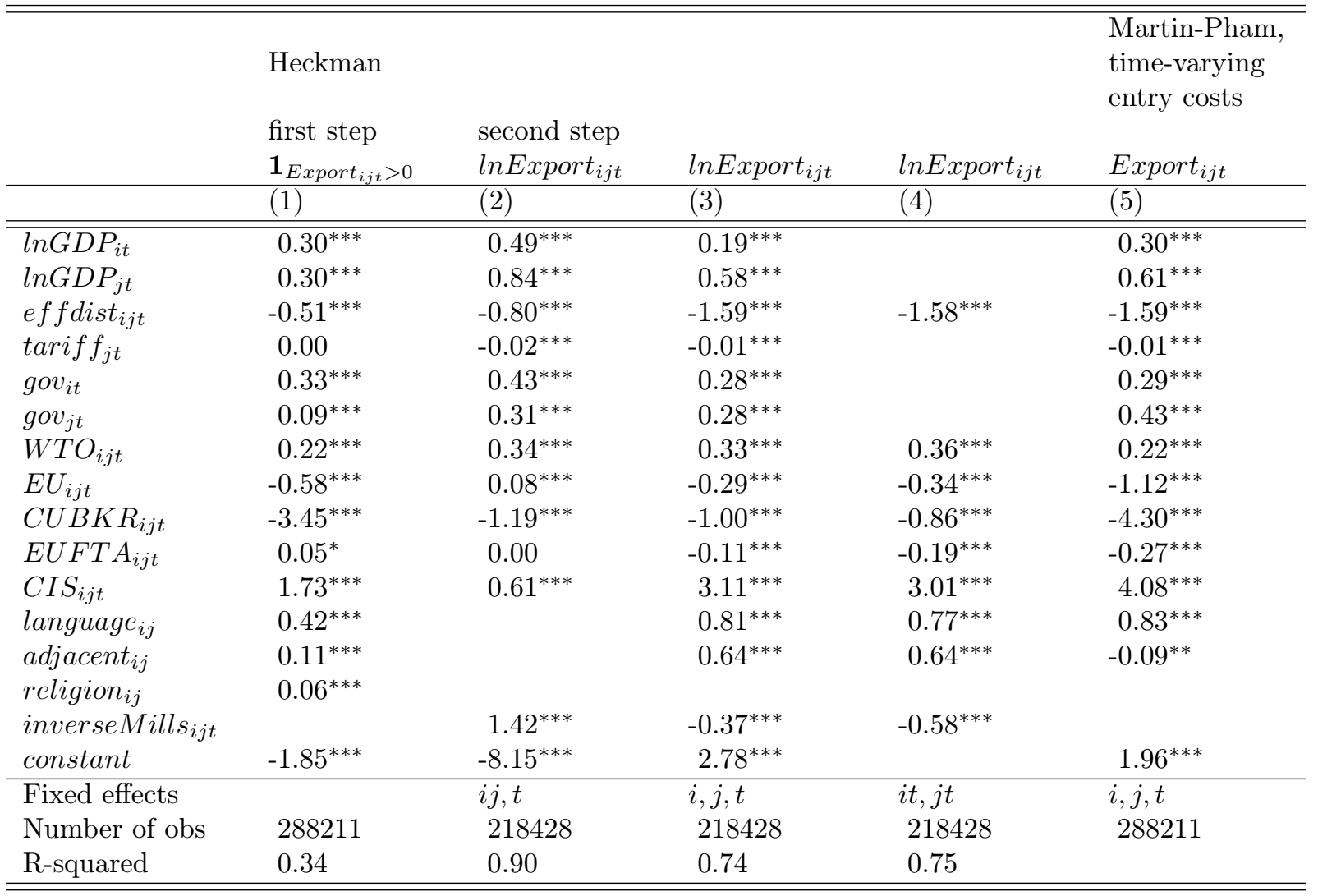

Notes: $(i)$ Dependent variables in the third row; $(i i)^{*}, * *, * * *$ denote statistical significance on the $10 \%, 5 \%$ and $1 \%$ levels respectively; (iii) Robust standard errors; ( $i v$ ) R-squared is computed as a squared correlation between a dependent variable and fitted values.

The estimation results for the PPML specification can be found in Table 6 for the nominal specification. We consider both a country-pair, time fixed effects specification as well as an individual-country effect in combination with a time effect specification. Furthermore, we also consider the truncated version of the PPML. As the estimation approaches are not likelihood based it is impossible to use the Vuong test for non-nested model comparison.

We focus the discussion of parameter interpretation on models with nominal variables. 
Table 5: Model performance relative to the performance of competing models.

\begin{tabular}{|c|c|c|c|c|}
\hline Model A & $\begin{array}{l}\text { Fixed } \\
\text { effects } \\
\text { specifica- } \\
\text { tion }\end{array}$ & Variables & $\begin{array}{l}\text { Number of } \\
\text { competing } \\
\text { models }\end{array}$ & $\begin{array}{l}\text { Percentage } \\
\text { of times } \\
\text { model A is } \\
\text { (strictly) } \\
\text { preferred }\end{array}$ \\
\hline Heckman & $i, j, t$ & nominal & 2 & $50 \%$ \\
\hline Heckman & $i j, t$ & nominal & 2 & $100 \%$ \\
\hline Heckman & $i t, j t$ & nominal & 2 & $0 \%$ \\
\hline Heckman & $i, j, t$ & real & 2 & $50 \%$ \\
\hline Heckman & $i j, t$ & real & 2 & $100 \%$ \\
\hline Heckman & $i t, j t$ & real & 2 & $0 \%$ \\
\hline Eaton-Tamura with time-invariant entry costs & $i, j, t$ & nominal & 7 & $14 \%$ \\
\hline Eaton-Tamura with time-variant entry costs & $i, j, t$ & nominal & 7 & $29 \%$ \\
\hline Martin-Pham with time-invariant entry costs & $i, j, t$ & nominal & 7 & $71 \%$ \\
\hline Martin-Pham with time-variant entry costs & $i, j, t$ & nominal & 7 & $86 \%$ \\
\hline Eaton-Tamura with time-invariant entry costs & $i, j, t$ & real & 7 & $0 \%$ \\
\hline Eaton-Tamura with time-variant entry costs & $i, j, t$ & real & 7 & $29 \%$ \\
\hline Martin-Pham with time-invariant entry costs & $i, j, t$ & real & 7 & $57 \%$ \\
\hline Martin-Pham with time-variant entry costs & $i, j, t$ & real & 7 & $\mathbf{8 6} \%$ \\
\hline
\end{tabular}

Notes: Competing models can be found in each panel.

The results for the real variables are rather similar. We obtain robust (with respect to model specification) and theory-consistent outcomes for a number of variables. In line with existing literature we obtain significant positive effects of GDPs on trade and significant negative effects of the effective distance. Tariff rate also affects trade adversely although it does not seem to impact the probability of trade. Robust positive effects on trade are found via improved governance. In all the model specifications in Table 4 governance indicators enter equations positively and significantly. We also obtain robust results on a number of trade agreements relevant for Ukraine. The membership of two countries in CIS free trade area shows a relatively strong positive coefficient in all the model specifications suggesting that CIS countries trade with each other more than a gravity model would predict. Conversely, membership in the customs union of Belarus, Kazakhstan and Russia does not seem to lead to higher trade flows even though we included anticipation effects since 2007. Negative coefficients are found in all the model specifications suggesting that the customs union members overtrade with each other under the CIS agreement. Finally, common language and WTO membership are found to promote trade. The latter effect is approximately of order of $24-40 \%$ all else equal and assuming constant inverse Mills coefficient.

While most of the variables take expected signs and, in addition, similar magnitudes across different specifications, the effect of EU agreements on trade is not as stable as expected. Estimates of EU and EUFTA dummies do not only change significance, but also change their sign under different specifications and under some specifications suggest that EU members trade less with each other than non-EU member states. Several observations might explain why these results occur. First, our sample is limited to 1997 - 2012, 
which means that only the countries that entered EU in 2004 and 2007 contribute to the estimation of the effect. The contribution of older members is absorbed by fixed effects. Thus, the effect might well be underestimated. Second, many countries that joined the EU in 2004 and 2007 have previously had special trade agreements with the union and therefore the $E U$ dummy may be in principle unable to capture the true effect. Third, integration efforts among non-EU economies may have had an even larger effect on their trade so that the gains from the EU agreement may have been relatively more moderate. Nevertheless, abstracting from possible limitations of using the $E U$ dummy, we do not find robust evidence with respect to EU or EUFTA membership. The effects are null or negative in Heckman specifications while positive in PPML. Based on this, therefore, we cannot conclude that direct gains from the creation of a trade agreement with EU will be positive and significant. Large and significant gains, however, are expected indirectly, via improved governance and improved infrastructure, the coefficients of which are robust and signed as expected throughout all the model specifications.

We note that the effect of the governance of the exporting country appears to be insignificant in the PPML specification of the gravity equation (see Table 6). However, we question the validity of PPML estimates since the results obtained using a full data sample are almost identical to those obtained using a truncated sample that only includes positive trade observations (see columns (3) and (4) of Table 6). This is in conflict with the outcome of Heckman models where non-zero trade observations have been found to significantly impact the results.

Table 6: Estimates of the gravity model using alternative estimation techniques.

\begin{tabular}{|c|c|c|c|c|}
\hline & \multicolumn{2}{|l|}{$\begin{array}{l}\text { PPML } \\
\text { Export }_{i j t}\end{array}$} & \multicolumn{2}{|c|}{$\begin{array}{l}\text { Truncated PPML } \\
\text { Export }_{i j t}\end{array}$} \\
\hline & $(1)$ & $(2)$ & $(3)$ & $(4)$ \\
\hline$\overline{l n} G D P_{i t}$ & $0.69^{* * *}$ & $0.73^{* * *}$ & $0.69^{* * *}$ & $0.72^{* * *}$ \\
\hline $\ln G D P_{j t}$ & $0.57^{* * *}$ & $0.57^{* * *}$ & $0.56^{* * *}$ & $0.56^{* * *}$ \\
\hline effdist $t_{i j t}$ & $-0.48^{* *}$ & $-0.80^{* * *}$ & $-0.55^{* *}$ & $-0.79^{* * *}$ \\
\hline $\operatorname{tarif} f_{j t}$ & $-0.03^{* * *}$ & $-0.03^{* * *}$ & $-0.03^{* * *}$ & $-0.03^{* * *}$ \\
\hline gov $_{i t}$ & 0.01 & 0.03 & 0.01 & 0.03 \\
\hline$g o v_{j t}$ & $0.29^{* * *}$ & $0.28^{* * *}$ & $0.26^{* * *}$ & $0.25^{* * *}$ \\
\hline$W T O_{i j t}$ & $0.23^{* * *}$ & $0.18^{* * *}$ & $0.24^{* * *}$ & $0.19^{* * *}$ \\
\hline$E U_{i j t}$ & $0.24^{* * *}$ & $0.37^{* * *}$ & $0.25^{* * *}$ & $0.38^{* * *}$ \\
\hline$C U B K R_{i j t}$ & $-0.65^{* * *}$ & $-0.56^{* * *}$ & $-0.54^{* * *}$ & $-0.31^{* *}$ \\
\hline$E U F T A_{i j t}$ & 0.04 & $0.25^{* * *}$ & 0.04 & $0.25^{* * *}$ \\
\hline$C I S_{i j t}$ & $0.35^{* *}$ & $1.68^{* * *}$ & $0.35^{* *}$ & $1.66^{* *}$ \\
\hline language $_{i j}$ & & $0.24^{* * *}$ & & $0.24^{* * *}$ \\
\hline adjacent $_{i j}$ & & $0.36^{* * *}$ & & $0.36^{* * *}$ \\
\hline Fixed effects & $i j, t$ & $i, j, t$ & $i j, t$ & $i, j, t$ \\
\hline Number of obs & 266592 & 288211 & 217650 & 218438 \\
\hline
\end{tabular}

Notes: (i) All the variables are in nominal terms; (ii) Dependent variables in the second row; $($ iii $) *, * *, * * *$ denote statistical significance on the $10 \%, 5 \%$ and $1 \%$ levels respectively; (iv) Robust standard errors.

An interesting outcome of our analysis are the estimates of the entry costs in EatonTamura and Martin-Pham model specifications. Figure 2 shows the dynamics of estimated 
initial costs. The results capture well the decreasing trend in global entry costs since 1997 and point to an increase in costs during the 2008/2009 recession.

Figure 2: Entry costs estimated by Eaton-Tamura and Martin-Pham specifications.

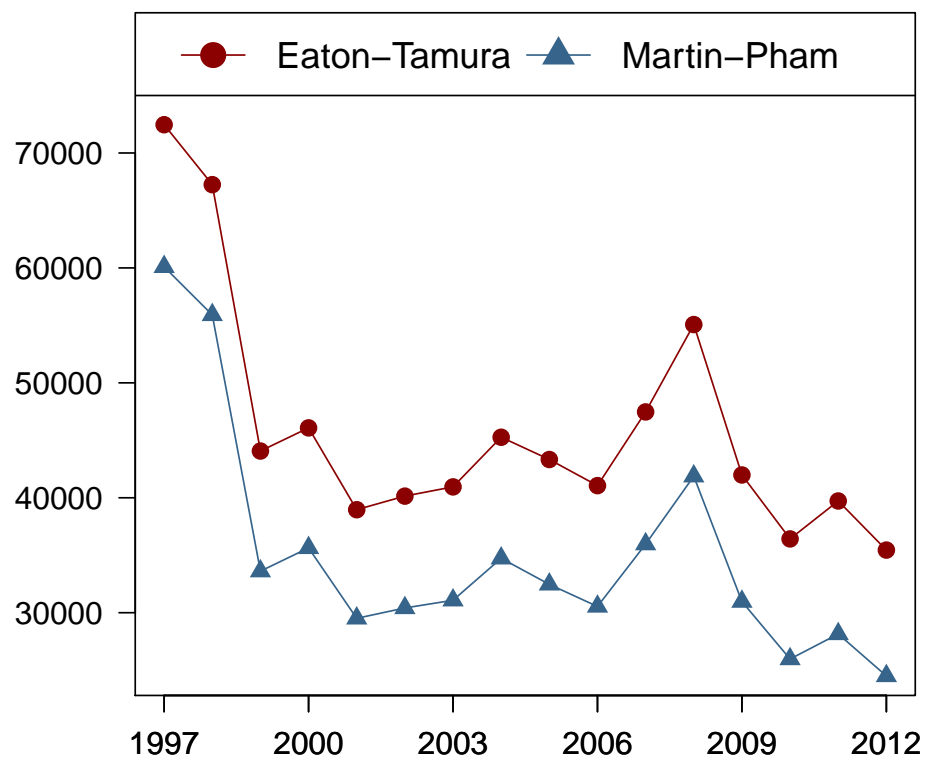

Note: Estimated coefficient $a_{t}$ in (5) expressed in US dollars.

Finally, in estimating gravity equations there is a concern of possible endogeneity of trade agreement variables. The decision on whether to form a free trade agreement is unlikely to be independent of the initial trade level between countries. However, the fixed effects included in our models should if not eliminate then at least lower the possible endogeneity bias by capturing differences in initial trade levels. Moreover, the variety of fixed effects deals well with possible endogeneity that may stem from unobserved heterogeneity (e.g. non-tariff measures specific to each country pair or domestic regulations that control international trade).

In the next section we perform several scenario analyses based on the estimation results. As the models with real dependent variable show similar results, we only focus on nominal models. Based on the test results, we consider for these analyses the Heckman model with $\eta_{i j}, \eta_{t}$ fixed effects, the Martin-Pham model with time-variant entry costs $a_{t}$ and the PPML.

\section{Scenario Analyses}

Model estimates in Table 4 lead to a set of robust results for a number of key variables. However, estimated elasticities do not necessarily represent the entire effect of those variables on export flows. Inference based on elasticities assumes that, for example, in a Heckman model, the Mills ratio does not play a role as a policy variable of interest changes. In this 
section we perform scenario analyses where we account for changes in the inverse Mills ratio.

For the scenario analyses, we use the fitted values of the models to quantify a number of counterfactuals. Particularly, we consider the following three questions: (i) what are the trade gains that are expected to accrue to Ukraine as it gains the EU access via a free trade area agreement compared to those of being a member of the customs union with Belarus, Kazakhstan and Russia? (ii) how would the trade pattern of Ukraine change if its level of infrastructure were to improve to reach the average value of EU-15? (iii) what would be the level of trade of Ukraine if it were to adopt the governance quality of Western economies?

As discussed at the end of the previous section, we consider the three best performing models selected in the previous section and we focus on the evolution at two margins: the intensive margin and the extensive margin. The intensive margin refers to a variation in the amount of trade of exporting firms that have already entered the foreign market. The extensive margin instead refers to trade that is created because new firms that did not export before enter the foreign market. We refer to Appendix A.5 for computational details.

The estimated coefficient of the EUFT $A_{i j t}$ dummy takes a significant negative value of $\hat{\alpha}_{E U F T A}=-0.27$ in the Martin-Pham specification of Table 4, a null value in the Heckman specification with country-pair and time fixed effects and a significant positive value of $\hat{\alpha}_{E U F T A}=0.25$ in the PPML specification with country specific fixed effects of Table 6 . There is therefore not enough evidence to reject the null hypothesis that trade between countries that have a free trade agreement with the $\mathrm{EU}$ is in line with gravity model predictions. There is not only lack of consensus on the significance, but neither it is on the sign of the effect. We approximate the bilateral EUFT $A_{i j t}$ effect by $e^{\hat{\alpha}_{E U F T A}}-1$ and report it as an entry of the second column of Table 7 . Similarly in the third column we obtain marginal trade effects of the customs union between Belarus, Kazakhstan and Russia. These are negative according to all model estimates. The results of Table 7 therefore point to an ambiguous effect of the free trade area with the EU and to a negative effect of the customs union between Belarus, Kazakhstan and Russia.

Table 7: Marginal trade effects of policy changes.

\begin{tabular}{lcc}
\hline \hline Model & $\begin{array}{c}\text { Free trade agreement } \\
\text { with EU }\left(E U F T A_{i j t}\right)\end{array}$ & $\begin{array}{c}\text { Customs union with } \\
\text { Belarus, Kazakhstan } \\
\text { and Russia } \\
\left(C U B K R_{i j t}\right)\end{array}$ \\
\hline \hline Heckman with $i j, t$ fixed effects & $0.00 \%$ & $-69.58 \%$ \\
Martin-Pham, time-varying entry costs & $-23.66 \%$ & $-98.64 \%$ \\
PPML with $i, j, t$ fixed effects & $28.40 \%$ & $-42.88 \%$ \\
\hline \hline
\end{tabular}

Note: The effects in Heckman model are computed conditional on trade being positive.

Trade benefits, however, are not limited to traditional policy instruments like the es- 
tablishment of free trade areas. The effects may be indirect and play a role via improved infrastructure or improved governance. Tables 8 and 9 illustrate the results. Scenario analyses are performed in a few steps. First, governance (resp. infrastructure) is lifted to the EU-15 average in 2012. In this specific case Ukrainian governance is lifted from -0.57 to 1.31 and Ukrainian infrastructure is lifted from 2.69 to 3.85 . This changes the model predicted probability of positive trade between a pair of countries. The difference in this probability averaged across all export destinations of Ukraine is then reported in column (1) of Tables 8 and 9. This outcome represents the extensive margin in probability terms. Namely, the percentage of all bilateral export flows that are no longer zero as a result of the policy change. Further, the intensive margin is obtained by computing the effect of the policy change on $X_{i j t}$ while conditioning on $X_{i j t}>0$ and while accounting for the change in the Mills ratio. The average of percentage changes across all export destinations gives then column (2) of Tables 8 and 9. Further as a next step the total effect of the policy change on $X_{i j t}$ is computed, i.e. when we do not condition on $X_{i j t}>0$. Again, the average of percentage changes across all export destinations gives then the total effect of the policy change on bilateral export flows after a correction has been made for the sample selection bias. This corresponds to column (4) of Tables 8 and 9. Finally, the difference between the total effect and the intensive margin gives column (2), i.e. the extent of the extensive margin in value terms. The exact formulas are available in Appendix A.5.

Tables 8 and 9 show robust outcomes, particularly with respect to the improvement in infrastructure. The results suggest that on average across all the three models the total effect of improving Ukraine's infrastructure to the EU-15 level would lead to a $22.31 \%$ increase in country's exports. Most of this increase originates from the intensive margin of trade. The last column of Table 9 also indicates that the impact of improved governance on Ukraine's exports can be as large as $126.54 \%$ following the results of the Heckman model. Martin-Pham model estimates deliver a lower gain while PPML suggests that the gain is insignificant. The latter result, however, is questionable as it conflicts with the results of all the remaining models and it does not seem to account well for zeros in trade.

Table 8: Trade effects of improved infrastructure.

\begin{tabular}{|c|c|c|c|c|}
\hline Model & $\begin{array}{c}\text { Extensive } \\
\text { Margin: } \\
\text { Change in } \\
\text { Probabil- } \\
\text { ity } \\
(\%)\end{array}$ & $\begin{array}{l}\text { Extensive } \\
\text { Margin: } \\
\text { Change in } \\
\text { Export } \\
\text { Flows }(\%)\end{array}$ & $\begin{array}{l}\text { Intensive } \\
\text { Margin: } \\
\text { Change in } \\
\text { Export } \\
\text { Flows }(\%)\end{array}$ & $\begin{array}{c}\text { Total } \\
\text { Country } \\
\text { Exports: } \\
\text { Change } \\
(\%)\end{array}$ \\
\hline & $(1)$ & $(2)$ & $(3)$ & $(4)$ \\
\hline Heckman with $i j, t$ fixed effects & 1.34 & 1.66 & 14.80 & 16.47 \\
\hline Martin-Pham, time-varying entry costs & 0.54 & 0.58 & 33.44 & 34.02 \\
\hline PPML with $i, j, t$ fixed effects & - & - & - & 16.43 \\
\hline
\end{tabular}


Table 9: Trade effects of improved governance.

\begin{tabular}{|c|c|c|c|c|}
\hline Model & $\begin{array}{c}\text { Extensive } \\
\text { Margin: } \\
\text { Change in } \\
\text { Probabil- } \\
\text { ity } \\
(\%)\end{array}$ & $\begin{array}{l}\text { Extensive } \\
\text { Margin: } \\
\text { Change in } \\
\text { Export } \\
\text { Flows (\%) }\end{array}$ & $\begin{array}{l}\text { Intensive } \\
\text { Margin: } \\
\text { Change in } \\
\text { Export } \\
\text { Flows (\%) }\end{array}$ & $\begin{array}{c}\text { Total } \\
\text { Country } \\
\text { Exports: } \\
\text { Change } \\
(\%)\end{array}$ \\
\hline & (1) & $(2)$ & (3) & (4) \\
\hline Heckman with $i j, t$ fixed effects & 6.23 & 12.80 & 113.73 & 126.54 \\
\hline Martin-Pham, time-varying entry costs & 0.81 & 1.02 & 67.93 & 68.96 \\
\hline PPML with $i, j, t$ fixed effects & - & - & - & 6.21 \\
\hline
\end{tabular}

\section{Policy Relevance}

Our empirical results enable to establish a hierarchy of policies. Estimated models suggest that most of the gains can be realized through improved governance. In our computations of counterfactuals we find that lifting governance of Ukraine to the EU-15 level would, all else equal, provide trade gains of around $98 \%$ on average. To a lesser extent but nevertheless significant is the quality of infrastructure that, according to our counterfactuals, could lead to on average $22 \%$ increase in Ukrainian exports if lifted to the EU-15 level. Significant trade benefits are associated with a WTO membership (approximately 24-40\%). Thus, directions for changes at the country level require commitment from Ukraine to increase the quality of its governance and infrastructure. Furthermore, the analysis provides evidence that, net of significant positive effects from reduced tariff rates, relatively small gains are expected from regional trading agreements. Our analysis suggests that access to the EU does not bring additional significant effects. Also, no positive trade boost was found resulting from the customs union between Belarus, Kazakhstan and Russia. It is questionable whether such a customs union will ever lead to positive trade effects since we find that CIS countries still substantially over-trade with each other. Not much has been said regarding the costs of implementing these policies. For example, an improvement in infrastructure requires large investments. However, the policy with the largest trade effects at both margins, namely, improved governance seems the cheapest to implement in economic terms.

\section{Conclusion}

This paper has analyzed alternative trade policy options for Ukraine. We focused on two scenarios. The first scenario evaluated possible consequences for Ukraine of closer economic integration with the EU (West). The second assessed possible outcomes of further integration with the CIS (East). Clearly, our results point to robust and significant indirect trade effects that would occur for Ukraine from closer economic ties with the EU. Particularly, the latter would certainly help to bring Ukraine's governance and infrastructure scores to a higher level. 
Our analysis was based on the results of the gravity model of trade estimated using three alternative estimation approaches that account for zeros in trade: Heckman twostage procedure, Martin-Pham tobit and PPML. We used a panel dataset of bilateral export flows among 159 world economies to obtain our results. Moreover, our approach included the application of statistical tests to select between competing models. We drew our conclusions from the non-linear scenario analysis of counterfactuals based on the results from the best performing models.

Our analysis has also yielded a number of robust results relevant for the general application of the gravity model of trade. We find that the inclusion of time-varying fixed effects does not improve the performance of an empirical model due to a large loss of degrees of freedom. Gravity model of trade that includes importer, exporter and time fixed effects is sufficient to fit the data. Furthermore, we find that models with nominal variables perform similarly to models with real variables if fixed effects are accounted for. Finally, our results show that PPML and truncated PPML yield almost identical results. This suggests that PPML may not always account well for the large number of zeros in trade.

\section{Acknowledgements}

We thank João Santos Silva for his helpful suggestions. 


\section{A Appendix}

\section{A.1 Included Countries}

\begin{tabular}{|c|c|c|c|}
\hline Afghanistan & Djibouti & Kyrgyzstan & Qatar \\
\hline Albania & Dominican Republic & Laos & Romania \\
\hline Algeria & Ecuador & Latvia & Russian Federation \\
\hline Angola & Egypt & Lebanon & Rwanda \\
\hline Argentina & El Salvador & Lesotho & Sao Tome and Principe \\
\hline Armenia & Eritrea & Liberia & Saudi Arabia \\
\hline Australia & Estonia & Libya & Senegal \\
\hline Austria & Ethiopia & Lithuania & Serbiaf \\
\hline Azerbaijan & Fiji & Luxembourg & Sierra Leone \\
\hline Bahamas & Finland & Macedonia & Singapore \\
\hline Bahrain & France & Madagascar & Slovakia \\
\hline Bangladesh & Gabon & Malawi & Slovenia \\
\hline Belarus & Gambia & Malaysia & Solomon Islands \\
\hline Belgium & Georgia & Maldives & South Africa \\
\hline Benin & Germany & Mali & Spain \\
\hline Bhutan & Ghana & Malta & Sri Lanka \\
\hline Bolivia & Greece & Mauritania & Sudan \\
\hline Bosnia and Herzegovir & Guatemala & Mauritius & Sweden \\
\hline Botswana & Guinea & Mexico & Switzerland \\
\hline Brazil & Guinea-Bissau & Moldova & Syria \\
\hline Bulgaria & Guyana & Mongolia & Tajikistan \\
\hline Burkina Faso & Haiti & Morocco & Tanzania \\
\hline Burundi & Honduras & Mozambique & Thailand \\
\hline Cambodia & Hong Kong & Namibia & Togo \\
\hline Cameroon & Hungary & Nepal & Tunisia \\
\hline Canada & Iceland & Netherlands & Turkey \\
\hline Chad & India & New Zealand & Turkmenistan \\
\hline Chile & Indonesia & Nicaragua & Uganda \\
\hline China & Iran & Niger & Ukraine \\
\hline Colombia & Iraq & Nigeria & United Arab Emirates \\
\hline Comoros & Ireland & Norway & United Kingdom \\
\hline Dem. Rep. of Congo & Israel & Oman & United States \\
\hline Rep. of Congo & Italy & Pakistan & Uruguay \\
\hline Costa Rica & Jamaica & Panama & Uzbekistan \\
\hline Cote d'Ivoire & Japan & Papua New Guinea & Venezuela \\
\hline Croatia & Jordan & Paraguay & Vietnam \\
\hline Cuba & Kazakhstan & Peru & Rep. of Yemen \\
\hline Cyprus & Kenya & Philippines & Zambia \\
\hline Czech Republic & Rep. of Korea & Poland & Zimbabwe \\
\hline Denmark & Kuwait & Portugal & \\
\hline
\end{tabular}




\section{A.2 Data Sources and Methods}

Table A.1: Data definitions and sources.

\begin{tabular}{ll}
\hline \hline Variable & Description \\
\hline \hline$X_{i j t}$ & $\begin{array}{l}\text { Exports of country } i \text { to country } j, \\
\text { f.o.b. value in million current US } \\
\text { dollars }\end{array}$ \\
& $\begin{array}{l}\text { Real exports of country } i \text { to coun- } \\
x_{i j t}\end{array}$ \\
try $j$
\end{tabular}

language $_{i j}$ Dummy for the common language

distance $_{i j} \quad$ Distance between countries $i$ and $j$ in $\mathrm{km}$ based on bilateral distances between the biggest cities of the two countries with inter-city distances being weighted by the share of the city in the overall country's population

religion $_{i j}$ Religion similarity index calculated as the product of the ratios for the exporting and importing country of people practising the same religion to the sum of people practising nine religions: Anglicanism, Buddhism, Catholicism, Confucianism, Hinduism, Islam, Judaism, Orthodoxy and Protestantism

infra.t $\quad$ Logistics performance index: quality of trade- and transport-related infrastructure

effdist ijt $_{\text {Effective distance (corrected for in- }}$ frastructure)

tariff $f_{j t}$ Tariff rate of country $j$, most favoured nation, weighted mean of all products, $\%$

$W T O_{i j t} \quad$ Dummy for the WTO membership (country $i$ and $j$ are both members at time $t$ )

$E U_{i j t} \quad$ Dummy for the EU membership (country $i$ and $j$ are both members at time $t$ )

$C U B K R_{i j t}$ Dummy for the membership in the customs union of Belarus, Kazakhstan and Russia (country $i$ and $j$ are both members at time $t$ )

\begin{tabular}{ll} 
Formula and notes & Source \\
\hline$x_{i j t}=\frac{X_{i j t} \times R G D P_{i t}}{G D P_{i t}}$ & IMF DOTS \\
& IMF DOTS, World Bank WDI \\
& World Bank WDI \\
& World Bank WDI
\end{tabular}

1 if countries $i$ and $j$ are contiguous; 0 otherwise

1 if common language is spoken at least by $9 \%$ of the population in countries $i$ and $j ; 0$ otherwise

$d_{i j}=\left(\sum_{k \in i} \sum_{l \in j} \frac{\text { pop }_{k}}{\text { pop }_{i}} \frac{\text { pop }_{l}}{\text { pop }_{j}} d_{k l}^{\theta}\right)^{1 / \theta}$ $\theta=-1$

religion $_{i j}=\sum_{k=1}^{9} \frac{r_{k i}}{\sum_{l=1}^{9} r_{l i}} \frac{r_{k j}}{\sum_{l=1}^{9} r_{l j}}$, $r_{k i}$ - number of people practising religion $k$ in country $i$, ranges from 0 to 1

CEPII, GeoDist database, Mayer and Zignano (2011), variable: contig

CEPII, GeoDist database, Mayer and Zignano (2011), variable: comlang_etno

CEPII, GeoDist database, Mayer and Zignano (2011), variable: distwces

Own calculations based on 2010 data from World Christian Database, http://worldchristiandatabase.org, dataset Religious makeup by country

ranges from 1 (low) to 5 (high)

World Bank WDI

effdist $t_{i j t}=\ln \left(\frac{d_{i j}}{i n f r a_{i t}+i n f r a_{j t}}\right) \quad$ Own calculations

World Bank WDI

1 if both countries $i$ and $j$ belong to www.wto.org

the WTO; 0 otherwise

1 if both countries $i$ and $j$ belong to EU; 0 otherwise

1 if both countries $i$ and $j$ belong to the customs union of Belarus, Kazakhstan and Russia; 0 otherwise www.tsouz.ru

Continued on next page 
Table A.1 - Continued from previous page

\begin{tabular}{|c|c|c|c|}
\hline $\begin{array}{l}\text { Variable } \\
\end{array}$ & Description & Formula and notes & Source \\
\hline$\overline{\overline{E U F T A_{i j t}}}$ & $\begin{array}{l}\text { Dummy for an FTA with the EU } \\
\text { of country } i \text { and } j\end{array}$ & $\begin{array}{l}1 \text { if country } i \text { is an EU country and } \\
\text { country } j \text { has an FTA with the EU } \\
\text { and vice versa: } 0 \text { otherwise }\end{array}$ & WTO RTA database \\
\hline CIS & $\begin{array}{l}\text { Dummy for CIS membership } \\
\text { (country } i \text { and } j \text { are both mem- } \\
\text { bers at time } t \text { ) }\end{array}$ & $\begin{array}{l}1 \text { if both countries } i \text { and } j \text { belong to } \\
\text { CIS; } 0 \text { otherwise }\end{array}$ & www.cisstat.com \\
\hline gov $_{\cdot t}$ & $\begin{array}{l}\text { Average governance score based } \\
\text { on: control of corruption, rule of } \\
\text { law, regulatory quality, voice and } \\
\text { accountability, government effec- } \\
\text { tiveness, political stability and ab- } \\
\text { sence of violence }\end{array}$ & $\begin{array}{l}\text { gov }_{\cdot t}=\left(\text { cor }_{\cdot t}+\text { law }_{\cdot t}+\text { reg }_{\cdot t}+\text { acc }_{\cdot t}+\right. \\
\left.\text { gov } \cdot t+\text { polstab }_{\cdot t}\right) / 6, \text { ranges from }-2.5 \\
\text { (low) to } 2.5(\text { high })\end{array}$ & $\begin{array}{l}\text { Own calculations based on } \\
\text { World Bank WGI database }\end{array}$ \\
\hline
\end{tabular}

Notes: (i) Data on infrastructure is available for 2007, 2010 and 2012. Missing data is interpolated using cubic splines and the earliest available data point (2007 for the majority of contries) was used to extrapolate the data till 1997; (ii) CIS dummy refers to CIS and not necessarily to CISFTA countries; ( $i i i)$ For a number of countries missing tariff rate data was interpolated using cubic splines; $(i v)$ The membership in the customs union of Belarus, Kazakhstan and Russia is assumed to be in force for the three countries since 2007 to take into account the anticipation effect. The actual enforcement took place in 2011. This does not bring sinificant changes to the estimated coefficient; $(v)$ Missing data on governance (years 1997, 1999, 2001) is interpolated using cubic splines. The definitions of the indicators are: (1) Voice and Accountability - capturing perceptions of the extent to which a country's citizens are able to participate in selecting their government, as well as freedom of expression, freedom of association, and a free media; (2) Political Stability and Absence of Violence/Terrorism - capturing perceptions of the likelihood of political instability and/or politically-motivated violence, including terrorism; (3) Government Effectiveness - capturing perceptions of the quality of public services, the quality of the civil service and the degree of its independence from political pressures, the quality of policy formulation and implementation, and the credibility of the government's commitment to such policies; (4) Regulatory Quality capturing perceptions of the ability of the government to formulate and implement sound policies and regulations that permit and promote private sector development; (5) Rule of Law - capturing perceptions of the extent to which agents have confidence in and abide by the rules of society, and in particular the quality of contract enforcement, property rights, the police, and the courts, as well as the likelihood of crime and violence; (6) Control of Corruption - capturing perceptions of the extent to which public power is exercised for private gain, including both petty and grand forms of corruption, as well as "capture" of the state by elites and private interests. 


\section{A.3 Parameter Estimation}

In this appendix we provide more details on the parameter estimation methods used in the paper.

\section{Heckman Model}

To estimate the parameters of the Heckman model (2)-(4) we use a two-step approach. In the first step the parameters of a probit model are estimated by Maximum Likelihood. The probit model relates the probability of trade between two countries to a set of explanatory variables

$$
\operatorname{Pr}\left(X_{i j t}^{*}=1 \mid \mathbf{W}_{i j t}\right)=\operatorname{Pr}\left(\mathbf{W}_{i j t}^{\prime} \beta+\epsilon_{i j t, 1}>0\right)=\Phi\left(\mathbf{W}_{i j t}^{\prime} \beta\right),
$$

where $\Phi(\cdot)$ is the cumulative distribution function of a standard normal distribution. In the second step we consider a linear panel data model explaining existing trade relationships $X_{i j t}>0$ as given in (4) where $\epsilon_{i j t, 2} \sim N\left(0, \sigma_{2}^{2}\right)$, where the correlation between the error terms of the probit and linear regression is represented by:

$$
E\left(\epsilon_{i j t, 1} \epsilon_{i j t, 2}\right)=\sigma_{12}
$$

The expected value of $\ln X_{i j t}$ given that $X_{i j t}>0$ is given by:

$$
E\left(\ln X_{i j t} \mid X_{i j t}>0, \mathbf{V}_{i j t}, \mathbf{W}_{i j t}\right)=\mathbf{V}_{i j t}^{\prime} \alpha+\eta_{i t}+\eta_{j t}+\sigma_{12} \frac{\phi\left(\mathbf{W}_{i j t}^{\prime} \beta\right)}{\Phi\left(\mathbf{W}_{i j t}^{\prime} \beta\right)},
$$

where $\phi(\cdot)$ is the density function of a standard normal distribution. To estimate the parameters of the linear regression (2nd step), we apply ordinary least squares to the original regression where we add the inverse Mills ratio $\frac{\phi\left(\mathbf{W}_{i j t}^{\prime} \beta\right)}{\Phi\left(\mathbf{W}_{i j t}^{\prime} \beta\right)}$ as extra explanatory variable to correct for the correlation between the probit and linear regression

$$
\ln X_{i j t}=\mathbf{V}_{i j t}^{\top} \alpha+\eta_{i t}+\eta_{j t}+\omega \frac{\phi\left(\mathbf{W}_{i j t}^{\prime} \hat{\beta}\right)}{\Phi\left(\mathbf{W}_{i j t}^{\prime} \hat{\beta}\right)}+u_{i j t},
$$

where $\hat{\beta}$ is obtained from the probit regression in the first step. The parameter $\hat{\omega}$ is the estimate for $\sigma_{12}$ and if it is significantly different from zero, the probit equation cannot be ignored. As the included Mills ratio is based on estimates, the resulting errors of the panel regression are heteroskedastic. For correct inference we opt therefore for White standard errors. Note that the test for $\omega=0$ relies on regular standard errors as under the null hypothesis the inverse Mills ratio disappears. For nonparametric identification of the model parameters, the vector $\mathbf{W}_{i j t}$ should include at least one explanatory variable which is not included in $\mathbf{Z}_{i j t}$. This excluded variable is one that is influential in determining the probability of trade but not the amount of trade. See Wooldridge (2002, Section 17.4) for more details. We use the religion similarity index for this purpose. 


\section{Eaton-Tamura Model}

To estimate the parameters of the Eaton-Tamura model (5) we use maximum likelihood. The likelihood function is given by

$$
L=\prod_{i, j, t}\left[\operatorname{Pr}\left(X_{i j t}=0\right) f_{X}\left(X_{i j t} \mid X_{i j t}=0\right)\right]^{1-d_{i j t}}\left[\operatorname{Pr}\left(X_{i j t}>0\right) f_{X}\left(X_{i j t} \mid X_{i j t}>0\right)\right]^{d_{i j t}},
$$

where $d_{i j t}$ is an indicator variable equal to 1 when exports $X_{i j t}$ are positive and 0 otherwise. Considering that $f_{X}\left(X_{i j t} \mid X_{i j t}=0\right)=1$ and $\operatorname{Pr}\left(X_{i j t}=0\right)=1-\Phi\left(\mathbf{V}_{i j t}^{\top} \alpha+\eta_{i}+\eta_{j}+\eta_{t}-\ln a_{t}\right)$ the log-likelihood simplifies to

$$
\ln L=\sum_{i, j, t}\left[\left(1-d_{i j t}\right)\left(1-\Phi\left(\mathbf{V}_{i j t}^{\top} \alpha+\eta_{i}+\eta_{j}+\eta_{t}-\ln a_{t}\right)\right)+d_{i j t} \ln \left(f\left(X_{i j t}+a_{t}\right)\right)\right],
$$

where $f$ is a log-normal density function:

$$
f\left(X_{i j t}+a_{t}\right)=\frac{1}{\left(X_{i j t}+a_{t}\right) \sqrt{2 \pi \sigma^{2}}} e^{-\frac{1}{2 \sigma^{2}}\left(\ln \left(X_{i j t}+a_{t}\right)-\mathbf{V}_{i j t}^{\top} \alpha-\eta_{i}-\eta_{j}-\eta_{t}\right)^{2}} .
$$

To obtain the estimates of $a_{t}, \alpha$ and fixed effects $\eta_{i}, \eta_{j}, \eta_{t}$ we maximize (8) using the NewtonRaphson algorithm.

\section{Pseudo-Poisson Maximum Likelihood}

The parameter estimates of the PPML estimator follow from a moment estimator based on (6)

$$
\left(\hat{\alpha}, \hat{\eta}_{i}, \hat{\eta}_{j}, \hat{\eta}_{t}\right)^{\boldsymbol{\top}}=\arg \min _{\alpha, \eta_{i}, \eta_{j}, \eta_{t}} \sum_{i, j, t}\left(X_{i j t}-e^{\mathbf{V}_{i j t}^{\top} \alpha+\eta_{i}+\eta_{j}+\eta_{t}}\right)^{2},
$$

The first-order conditions correspond with the first-order conditions of a Poisson model. The estimator attributes the same weight to all observations. A log-linear specification gives more weight to observations with high $e^{\mathbf{V}_{i j t}^{\prime} \alpha+\eta_{i}+\eta_{j}+\eta_{t}}$. As long as the pattern of heteroskedasticity increases with $e^{\mathbf{V}_{i j t}^{\prime} \alpha+\eta_{i}+\eta_{j}+\eta_{t}}$ this approach results in a more efficient estimator as it does not give more weight to "noisier" observations.

The method also overcomes a potential bias arising due to the estimation of elasticities by using a log-linear form of a gravity equation. The fact stems from Jensen's inequality which states that the expectation of the log of the error term is not equal to the log of the expectation. 


\section{A.4 Estimation Results for Real Variables}

Table A.2: Estimates of the gravity model using alternative estimation techniques.

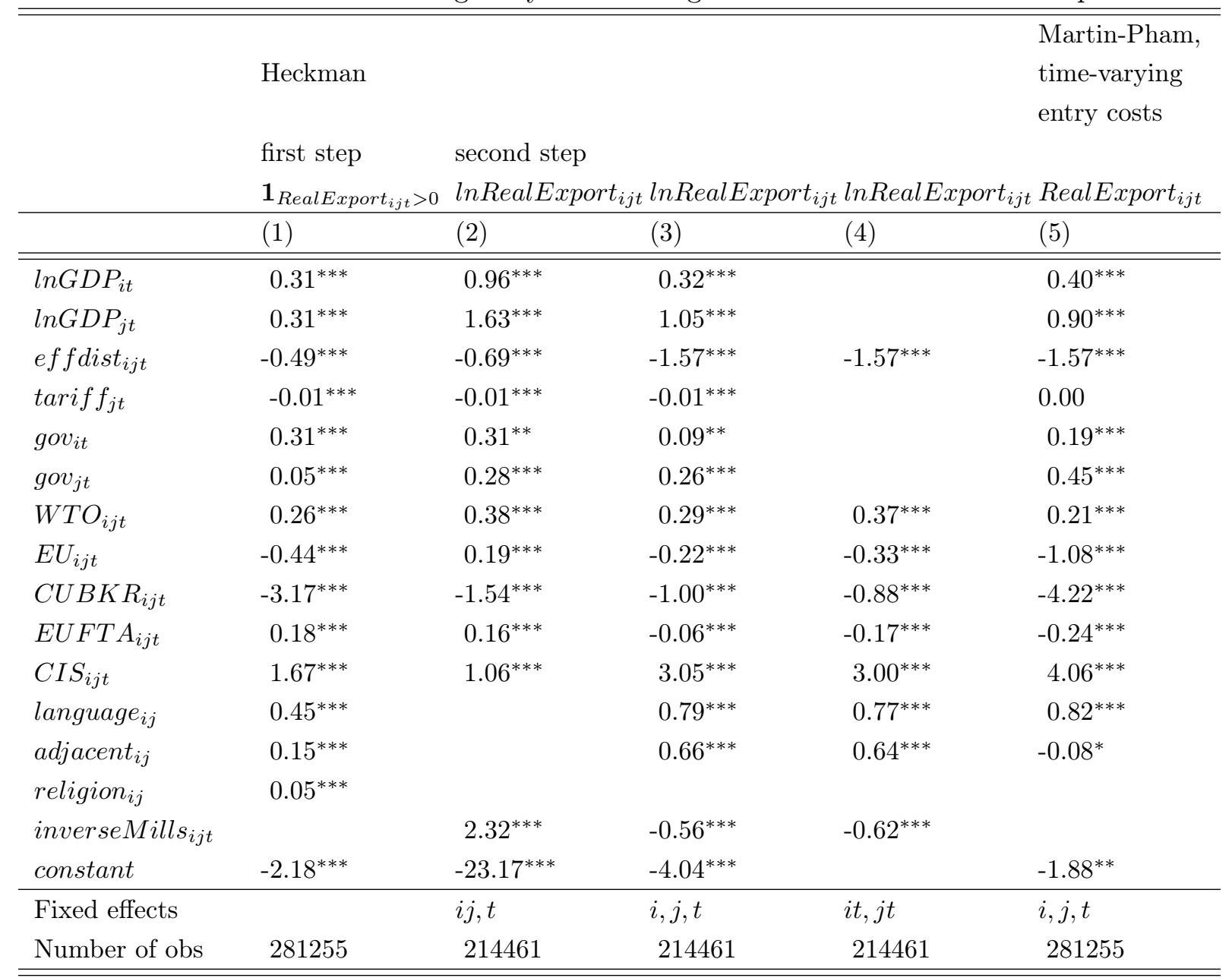

Notes: $(i)$ All the variables are in real terms; (ii) Dependent variables in the third row; (iii) *, **, *** denote statistical significance on the $10 \%, 5 \%$ and $1 \%$ levels respectively; (iv) Robust standard errors.

\section{A.5 Computations of the Intensive and Extensive Margins}

Besides dealing with zero trades, the Heckman and Eaton-Tamura models provide estimates of the intensive and extensive margins of trade. The former refers to the change in sales of incumbent exporters after a policy change, the latter to the change in sales of new entrants.

\section{Heckman Model}

Suppose that because of a policy change the $k$ th explanatory variable $w_{k, i j t}=v_{k, i j t} \in\left\{\mathbf{W}_{i j t}^{\prime}, \mathbf{V}_{i j t}^{\prime}\right\}$ in (2) and/or (4) increases from $a$ to $b$. In the Heckman framework, all else equal, the policy change transforms the estimated probability of positive trade between two countries as follows:

$$
\left.\operatorname{Pr}\left(X_{i j t}^{*}=1 \mid \mathbf{W}_{i j t}\right)\right|_{w_{k, i j t}=b}-\left.\operatorname{Pr}\left(X_{i j t}^{*}=1 \mid \mathbf{W}_{i j t}\right)\right|_{w_{k, i j t}=a}=\left.\Phi\left(\mathbf{W}_{i j t}^{\top} \hat{\beta}\right)\right|_{w_{k, i j t}=b}-\left.\Phi\left(\mathbf{W}_{i j t}^{\boldsymbol{\top}} \hat{\beta}\right)\right|_{w_{k, i j t}=a}
$$


where the notation $\left.\right|_{w_{i j t}=a}$ means "evaluate the function at $a$ ". This outcome follows directly from (7). The average across all export destinations of a selected country $i$ (e.g. Ukraine) represents the extensive margin in probability terms, i.e. the percentage of all potential bilateral export flows that are no longer zero as a result of the policy change. This result is shown in column (1) of Tables 8 and 9 .

The entrance of new exporters ${ }^{11}$ to the market affects incumbents' trade flows. This effect arises in incumbents' equation (4) via the inverse Mills ratio. To estimate this effect we use conditional expectation, i.e. expected export flow from country $i$ to country $j$ (in levels) given that there is trade between these two countries:

$$
E\left(X_{i j t} \mid X_{i j t}>0, \mathbf{V}_{i j t}^{\prime}, \mathbf{W}_{i j t}^{\prime}\right)=\exp \left(\mathbf{V}_{i j t}^{\top} \alpha+\eta_{i t}+\eta_{j t}+1 / 2 \sigma_{2}^{2}\right) \frac{\Phi\left(\mathbf{W}_{i j t}^{\top} \beta+\sigma_{12}\right)}{\Phi\left(\mathbf{W}_{i j t}^{\prime} \beta\right)}
$$

An intensive margin of trade is then a percentage change in this conditional expectation:

$$
\begin{aligned}
\left.\left.\frac{E\left(X_{i j t} \mid X_{i j t}>0, \mathbf{V}_{i j t}^{\prime},\right.}{E\left(X_{i j t} \mid X_{i j t}>0, \mathbf{V}_{i j t}^{\prime},\right.}, \mathbf{W}_{i j t}^{\prime}\right)\left.\right|_{w_{k, i j t}=b}\right)_{w_{k, i j t}=a} & -1 \\
= & \exp \left((b-a) \alpha_{k}\right) \frac{\left.\Phi\left(\mathbf{W}_{i j t}^{\prime} \beta+\sigma_{12}\right)\right|_{w_{k, i j t}=b}}{\left.\Phi\left(\mathbf{W}_{i j t}^{\prime} \beta\right)\right|_{w_{k, i j t}=b}} \frac{\left.\Phi\left(\mathbf{W}_{i j t}^{\prime} \beta\right)\right|_{w_{k, i j t}=a}}{\left.\Phi\left(\mathbf{W}_{i j t}^{\prime} \beta+\sigma_{12}\right)\right|_{w_{k, i j t}=a}}-1
\end{aligned}
$$

To obtain an estimate we replace model parameters $\alpha_{k}, \sigma_{12}, \beta$ with their estimated values $\hat{\alpha}_{k}, \hat{\omega}$, $\hat{\beta}$. The average across all export destinations gives then an estimate of the intensive margin of trade after a correction has been made for the entry of new exporters. We report the result in column (3) of Tables 8 and 9 . To compute the total (unconditional) change of the policy change we use the unconditional expectation for export flows in levels given by:

$$
E\left(X_{i j t} \mid \mathbf{V}_{i j t}^{\prime}, \mathbf{W}_{i j t}^{\prime}\right)=\exp \left(\mathbf{V}_{i j t}^{\top} \alpha+\eta_{i t}+\eta_{j t}+1 / 2 \sigma_{2}^{2}\right) \Phi\left(\mathbf{W}_{i j t}^{\top} \beta+\sigma_{12}\right)
$$

The unconditional percentage change in the bilateral export flow as a result of the policy change is then:

$$
\frac{\left.E\left(X_{i j t} \mid \mathbf{V}_{i j t}^{\prime}, \mathbf{W}_{i j t}^{\prime}\right)\right|_{w_{k, i j t}=b}}{E\left(X_{i j t} \mid \mathbf{V}_{i j t}^{\prime}, \mathbf{W}_{i j t}^{\prime}\right)_{w_{k, i j t}=a}}-1=\exp \left((b-a) \alpha_{k}\right) \frac{\left.\Phi\left(\mathbf{W}_{i j t}^{\prime} \beta+\sigma_{12}\right)\right|_{w_{k, i j t}=b}}{\left.\Phi\left(\mathbf{W}_{i j t}^{\prime} \beta+\sigma_{12}\right)\right|_{w_{k, i j t}=a}}-1
$$

Again, we average across all export destinations of Ukraine. This gives the total effect of the policy change on bilateral trade flows after correction for the sample selection bias. We report the outcome in column (4) of Tables 8 and 9 .

The difference between the total change and the intensive margin gives then the extent of the extensive margin, i.e. the value of exports of newly entered firms. This is column (2) of Tables 8 and 9 .

\section{Eaton-Tamura Model}

In Eaton-Tamura model (5) the effect of policy change on the probability of non zero trade between two countries is computed as follows:

\footnotetext{
${ }^{11}$ If the policy change is negative some firms may exit the market giving a negative extensive margin in probability terms.
} 


$$
\begin{aligned}
& \left.\operatorname{Pr}\left(X_{i j t}>0 \mid \mathbf{V}_{i j t}^{\prime}\right)\right|_{v_{k, i j t}=b}-\left.\operatorname{Pr}\left(X_{i j t}>0 \mid \mathbf{V}_{i j t}^{\prime}\right)\right|_{v_{k, i j t}=a} \\
& =\left.\Phi\left(-\frac{\ln a_{t}-\mathbf{V}_{i j t}^{\prime} \alpha-\eta_{i}-\eta_{j}-\eta_{t}}{\sigma_{i j t}}\right)\right|_{v_{k, i j t}=b}-\left.\Phi\left(-\frac{\ln a_{t}-\mathbf{V}_{i j t}^{\prime} \alpha-\eta_{i}-\eta_{j}-\eta_{t}}{\sigma_{i j t}}\right)\right|_{v_{k, i j t}=a}
\end{aligned}
$$

Like in Heckman model the average across all export destinations of a selected country $i$ gives the extensive margin in probability terms (column (1) of Tables 8 and 9), where we replace the parameters with their ML estimates.

From the structure of the Eaton-Tamura model it follows that $Q_{i j t}=Z_{i j t}+a_{t}$ is a lognormal random variable with the mean $\mu_{i j t}=\mathbf{V}_{i j t}^{\prime} \alpha+\eta_{i}+\eta_{j}+\eta_{t}$ and the variance $\sigma_{i j t}^{2}$. This gives the conditional expectation necessary to compute the intensive margin:

$E\left(X_{i j t} \mid X_{i j t}>0, \mathbf{V}_{i j t}^{\prime}\right)=E\left(Q_{i j t}-a_{t} \mid Q_{i t}>a_{t}, \mathbf{V}_{i j t}^{\prime}\right)=\exp \left(\mu_{i j t}+\sigma_{i j t}^{2} / 2\right) \frac{\Phi\left(\frac{\mu_{i j t}+\sigma_{i j t}^{2}-\ln a_{t}}{\sigma_{i j t}}\right)}{\Phi\left(-\frac{\ln a_{t}-\mu_{i j t}}{\sigma_{i j t}}\right)}-a_{t}$,

and the unconditional expectation relevant for the computation of the total effect of the policy change:

$E\left(X_{i j t} \mid \mathbf{V}_{i j t}^{\prime}\right)=E\left(X_{i j t} \mid X_{i j t}>0, \mathbf{V}_{i j t}^{\prime}\right) \operatorname{Pr}\left(X_{i j t}>0 \mid \mathbf{V}_{i j t}^{\prime}\right)=E\left(X_{i j t} \mid X_{i j t}>0, \mathbf{V}_{i j t}^{\prime}\right) \Phi\left(-\frac{\ln a_{t}-\mu_{i j t}}{\sigma_{i j t}}\right)$.

The intensive margin, the extensive margin in value terms and the total effect of the policy change are computed in the same way as for the Heckman model using the relevant conditional and unconditional expectations and the ML parameters estimates. 


\section{References}

Acemoğlu, D. and Robinson, J.A. (2012), Why Nations Fail (New York: Crown Publishers)

Anderson, J.E. (1979), "A Theoretical Foundation for the Gravity Equation," American Economic Review, 69, 106-116.

Anderson, J.E. and van Wincoop, E. (2003), "Gravity with Gravitas: A Solution to the Border Puzzle," American Economic Review, 93, 170-192.

Baldwin, R. and Taglioni, D. (2007), "Trade Effects of the Euro: a Comparison of Estimators," Journal of Economic Integration, 22(4), 780-818.

Baltagi, B.H., Egger, P., and Pfaffermayr, M. (2003), "A Generalized Design for Bilateral Trade Flow Models," Economics Letters, 80, 391-397.

Bergstrand, J.H. (1989), "The Generalized Gravity Equation, Monopolistic Competition, and the Factor-Proportions Theory in International Trade," Review of Economics and Statistics, 71(1), 143-153.

Cheng, I-H. and Wall, H.J. (2005), "Controlling for Heterogeneity in Gravity Models of Trade and Integration," Review of the Federal Reserve Bank of St. Louis, 87, 49-63.

Clarke, K.A. (2007), "A Simple Distribution-Free Test for Nonnested Model Selection," Political Analysis, 15(3), 347-363.

Costinot, A. (2009), "On the Origins of Comparative Advantage," Journal of International Economics, 77(2), 255-264.

Cuñat, A. and Melitz, M.J. (2010), "A Many-Country, Many-Good Model of Labor Market Rigidities as a Source of Comparative Advantage," Journal of the European Economic Association, 8(2-3), 434-441.

Cuñat, A. and Melitz, M.J. (2012), "Volatility, Labor Market Flexibility, and the Pattern of Comparative Advantage," Journal of the European Economic Association, 10, 225-254.

Deardorff, A.V. (1998), "Determinants of Bilateral Trade: Does Gravity Work in a Neoclassical World?" in The Regionalism of the World Economy, ed. by J.A. Frankel (Chicago: University of Chicago Press), 7-28.

Dixit, A. (1992), "Investment and Hysteresis," Journal of Economic Perspectives, 6(1), 107-132.

Eaton, J. and Kortum, S. (2002), "Technology, Geography, and Trade," Econometrica, 70, $1741-1779$.

Eaton, J. and Tamura, A.K. (1994), "Bilateralism and Regionalism in Japanese and U.S. Trade and Direct Foreign Investment Patterns," Journal of the Japanese and International Economies, 8, 478-510.

Egger, P. (2000), "A Note on the Proper Econometric Specification of the Gravity Equation," Economics Letters, 66, 25-31. 
Francois, J. and Manchin, M. (2013), "Institutions, Infrastructure, and Trade," World Development, $46(\mathrm{C}), 165-175$.

Glick, R. and Rose, A.K. (2002), "Does a Currency Union Affect Trade? The Time Series Evidence," European Economic Review, 46, 1125-1151.

Grigoriou, C. (2007), "Landlockedness, Infrastructure and Trade : New Estimates for Central Asian Countries," World Bank Policy Research Working Papers, 4335.

Hausmann, R. and Rodrik D. (2003), "Economic Development as Self-Discovery," Journal of Economic Development, 72, 603-633.

Harrison, E.A. and Rodríguez-Clare, A. (2009) , "Trade, Foreign Investment and Industrial Policy," in Handbook of Development Economics, ed. by D. Rodrick and M.R. Rosenzweig, vol. 5 (Amsterdam: North Holland), chapter 63.

Heckman, J. (1979), "Sample Selection Bias as a Specification Error," Econometrica, 47(1), 153-161.

Head, K. and Mayer, T. (2014), "Gravity Equations: Workhorse, Toolkit and Cookbook," in Handbook of International Economics, ed. by G. Gopinath, E. Helpman and K. Rogoff, vol. 4 (Amsterdam: North Holland), chapter 3.

Helpman, E., Melitz, M. and Rubinstein, Y. (2008), "Estimating Trade Flows: Trading Partners and Trading Volumes," Quarterly Journal of Economics, 123(2), 441-487.

Levchenko, A.A. (2004), "Institutional Quality and International Trade," Review of Economic Studies, 74(3), 791-819.

Mayer, T. and Zignago, S. (2011), "Notes on CEPII's Distances Measures: the GeoDist Database," CEPII Working Paper, 25.

Martin, W. and Pham, C.S. (2015), "Estimating the Gravity Model When Zero Trade Flows are Frequent and Economically Determined," World Bank Policy Research Working Paper, 7308.

Mátyás, L. (1997), "Proper Econometric Specification of the Gravity Model," The World Economy, 20(3), 363-368.

Nunn, N. (2007), "Relationship-Specificity, Incomplete Contracts, and the Pattern of Trade," Quarterly Journal of Economics, 122(2), 569-600.

Santos Silva, J.M.C. and Tenreyro, S. (2006), "The Log of Gravity," Review of Economics and Statistics, 88(4), 641-658.

Shepherd, B. and Wilson, J.S. (2009), "Trade Facilitation in ASEAN Member Countries: Measuring Progress and Assessing Priorities," Journal of Asian Economics, 20(4), 367383.

Vuong, Q. (1989). "Likelihood Ratio Tests for Model Selection and Non-Nested Hypotheses," Econometrica, 57, 307-333.

Wooldridge, J.M. (2002), Econometric Analysis of Cross Section and Panel Data (Boston, MA: The MIT Press). 